\title{
Prolactin (PRL), placenta growth factor (PIGF) and nerve growth factor receptor (NGFR) as biomarkers for early diagnosis and prognosis in patients with esophageal squamous cell carcinoma (ESCC)
}

\author{
Xiaohong Ai ${ }^{1,2}$, Xiaoxi Zhu ${ }^{1,2}$, Jianhong Zuo ${ }^{1,2,3,4}$ \\ ${ }^{1}$ Department of Radiotherapy, The First Affiliated Hospital, ${ }^{2}$ Hunan Province Key Laboratory of Tumor Cellular and Molecular Pathology, Cancer \\ Research Institute, School of Medicine, ${ }^{3}$ The Translational Medicine Laboratory, Hengyang Medical College, ${ }^{4}$ The Third Affiliated Hospital, \\ University of South China, Hengyang 421900, China \\ Contributions: (I) Conception and design: J Zuo, X Ai; (II) Administrative support: J Zuo, X Ai; (III) Provision of study materials or patients: X Zhu; \\ (IV) Collection and assembly of data: X Zhu; (V) Data analysis and interpretation: X Zhu; (VI) Manuscript writing: All authors; (VII) Final approval \\ of manuscript: All authors. \\ Correspondence to: Jianhong Zuo. University of South China, Hengyang 421900, China. Email: 632138414@qq.com.
}

Background: The purpose of this study was to investigate the expression and clinical significance of prolactin (PRL), placenta growth factor (PIGF) and nerve growth factor receptor (NGFR) in esophageal squamous cell carcinoma (ESCC).

Methods: PRL, PIGF and NGFR were selected through being screened normal human and esophageal cancer (EC) plasma by high-throughput protein chips. Subsequently, enzyme linked immunosorbent assay (ELISA) and immunohistochemistry (IHC) were used to detect the expression in ESCC and control group. Then, its clinical significance was statistically evaluated.

Results: The expression of PRL, PIGF and NGFR in plasma and tissue of patients with EC was higher than healthy controls and adjacent tissue, respectively. Among the clinical parameters, the expression of PRL and NGFR protein was correlated with the tumor classification of ESCC $(\mathrm{P}<0.05)$, while PIGF protein was correlated with the clinical stage of ESCC $(\mathrm{P}<0.05)$. The area under the ROC (AUC) of PRL, PIGF, and NGFR in plasma was $0.69,0.72$, and 0.66 in separately. Furthermore, the combined detection of three proteins had a better AUC of 0.74 with a sensitivity of $66.7 \%$ and a specificity of $72.4 \%$. KaplanMeier survival analysis revealed that positive expression of PRL, PIGF and NGFR in histological predicted significantly worse overall survival (OS) than negative expression $(\mathrm{P}<0.05)$.

Conclusions: PRL, PIGF and NGFR are promising biomarkers for diagnosis and prognosis prediction of ESCC.

Keywords: Esophageal squamous cell carcinoma (ESCC); PRL; placenta growth factor (PIGF); nerve growth factor receptor (NGFR)

Submitted Feb 20, 2019. Accepted for publication Oct 25, 2019.

doi: $10.21037 /$ tcr.2019.12.31

View this article at: http://dx.doi.org/10.21037/tcr.2019.12.31

\section{Introduction}

$\mathrm{EC}$ is one of the most frequent cancers and the leading cause of cancer-related death in the world (1). The 2018 global esophageal epidemiology declared that there was a total of about 456,000 cases of EC. Among them, more than 398,000 were esophageal squamous cell carcinoma (ESCC), where there were more than 315,000 in Central Asia and Southeast Asia. There were 210,000 cases in China 
consisting of alone 52,000 cases of adenocarcinoma (ACA) and 6,000 cases of other cancers, such as neuroendocrine, choriocarcinoma (2). The global incidence of ESCC is $5.2 / 100,000$, and incidence of esophageal adenocarcinoma is $0.7 / 100,000$ (3). The $98 \%$ pathological classification of EC is squamous cell carcinoma in China, therefore ESCC is one of the distinctive tumors (4).

Most patients with early EC are asymptomatic and often diagnosed at an advanced stage (5). The 5 -year OS is about $15-20 \%$ (6), so early diagnosis is particularly important to improve. Presently, the early diagnosis of EC is mainly based on clinical symptoms, radiological investigations, laboratory tests and endoscopic biopsy (7-9). The disadvantages of them are time consuming, high cost, poor patient tolerance, and low detection rate (10). The urgent requirement is looking for a low-cost, convenient and rapid diagnostic method to improve the prognosis of EC (11). Compared with a diagnosis based on endoscopic biopsy, the assessment of tumor markers in plasma have the advantages of being simple to perform and highly specific (12). But none of marker have been shown to have significance for EC diagnosis thus far $(13,14)$. Therefore, the aim of study is to explore and validate potential tumor markers for EC. $\mathrm{EC}$ is one of the common malignant tumors in the digestive tract, and its specific pathogenesis had not been fully elucidated.

\section{Methods}

\section{Plasma samples}

Plasma samples were selected from 80 patients with ESCC confirmed by gastroscopy biopsy and postoperative pathology at the First Affiliated Hospital of University of South China from April 2016 to April 2017. The study was approved by ethics committee of the First Affiliated Hospital of University of South China and all participants signed the agreement. According to whether they received tumor-related treatment, 35 patients were pre-treatment samples and 45 patients were post-treatment samples including 15 patients who underwent surgery, 18 patients who received radiation therapy, and 12 patients who received chemotherapy. The efficacy of all patients in the treatment group was assessed as a complete response (CR). Forty-eight healthy controls who were confirmed to have no cancer who was inspected clinically and visually by the medical center as a control group. All plasma samples were cryopreserved at $-80^{\circ} \mathrm{C}$.

\section{Plasma protein chip detection}

Sample dilution was added $100 \mu \mathrm{L}$ to each well and incubated for $1 \mathrm{~h}$ at room temperature (RT) to block the quantitative antibody chip (RayBiotech, America). The buffer in each well was removed, and $100 \mu \mathrm{L}$ of the sample was added to the well and incubated overnight at $4{ }^{\circ} \mathrm{C}$. The antibody mixture tube was centrifuged and then $1 \mathrm{~mL}$ of the sample dilution was added. Eighty $\mu \mathrm{L}$ of the detection antibody was added to each well and incubated on the shaker for $2 \mathrm{~h}$. Cy3-streptavidin was incubated and centrifuged, then $1.4 \mathrm{~mL}$ of the sample dilution was added and mixed well and centrifuged again quickly. Eighty $\mu \mathrm{L}$ of $\mathrm{Cy} 3$-streptavidin was added to each well, and the slide was wrapped in aluminum foil to protect from light and incubated for $1 \mathrm{~h}$ on the shaker. Data analysis InnoScan 300 Microarray Scanner was used.

\section{Enzyme linked immunosorbent assay (ELISA)}

Three $\mathrm{mL}$ of plasma was isolated by centrifuging the tubes at $250 \mathrm{~g}$ for 10 minutes. The wells of a 96-well microplate were coated with capture antibody prolactin (PRL) (R\&D, America), placenta growth factor (PIGF) (R\&D, America) or nerve growth factor receptor (NGFR) (R\&D, America) with $30 \mu \mathrm{L}$ of coating buffer $(0.1 \mathrm{M}$ sodium carbonatesodium bicarbonate, $\mathrm{PH} 9.5 ; 1.59 \mathrm{~g} \mathrm{Na}_{2} \mathrm{CO}_{3}$ and $7.13 \mathrm{~g}$

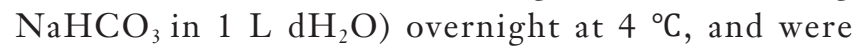
removed the coating buffer for adding $50 \mu \mathrm{L}$ blocking buffer $(1 \mathrm{~mL}$ PBS $)$ at RT BSA\%. Protein samples $(30 \mu \mathrm{L})$ were pre-mixed with dilution buffer (PBST, $30 \mu \mathrm{L}$ PBS, PH 7.4, containing $0.05 \%$ Tween $20,1 \%$ BSA and $5 \mu \mathrm{g}$ protein) for $1 \mathrm{~h}$. The mixture was loaded and incubated for $1 \mathrm{~h}$ at RT, and the plate was washed three times with PBST. Next, $30 \mu \mathrm{L}$ of the detection antibody (R\&D, America) in the dilution buffer was separately added. The plates were incubated for $1 \mathrm{~h}$ at RT and washed three times with PBST. The reaction was observed by adding $30 \mu \mathrm{L} /$ well of TMB substrate solution (R\&D, America) at RT for 30 minutes. The reaction was stopped with $30 \mu \mathrm{L} /$ well of stop solution $\left(\mathrm{NaH}_{2} \mathrm{SO}_{4}\right)$. ELISA plates were detected at $450 \mathrm{~nm}$ using an Epoch microplate spectrophotometer (Bio-Tek).

\section{Tissue samples}

Samples were obtained from patients including 53 men and 15 women, ranging in age from 38 to 82 years, with a median age of 62 years, with EC who underwent surgical 
resection from February 2012 to February 2013 at the First Affiliated Hospital of University of South China. None of them had received radiotherapy or chemotherapy before surgery. Informed consent was obtained from all of the EC patients. The study was approved by the research ethics committee of the First Affiliated Hospital of University of South China. Among 68 cases of EC, 33 cases were classified as High-middle differentiation and 35 cases as poorly differentiated. There are 38 cases classified as I-II phase and 30 cases as III-IV phase. The clinicopathological standards were determined according to the classification of malignant tumors as set out by the World Health Organization (15) and the International Union Against Cancer Tumor-Node-Metastasis (TNM) staging system (16). The expression levels of the PRL, PIGF and NGFR in ESCC tissue and adjacent tissue were detected by immunohistochemistry (IHC).

\section{IHC}

The sections were deparaffinized with xylene, and the paraffin-embedded tissue sections were fixed in xylene for 10 minutes and then hydrated with absolute ethanol I (100\%), absolute ethanol II (95\%). Sections were treated with TE buffer (10 $\mathrm{mM}$ Tris and $1 \mathrm{mM}, \mathrm{pH}$ 9.2) for 25 minutes in a microwave oven. To reduce non-specific staining, each section was blocked with $3 \%$ bovine serum albumin in PBS for 30 minutes. The sections were then incubated with antibody PRL (Proteintech Group, China), PIGF (Proteintech Group, China), NGFR (Proteintech Group, China) for $1 \mathrm{~h}$ at RT, and washed continuously with PBS buffer. The sections were then incubated with antiincubated mouse/rabbit antibody (Envision plus, Dako, Denmark) for 30 minutes at RT. The protoplast was an Imm PACTAEC peroxidase substrate (VECTOR Laboratories) for 20 minutes. The sections were counterstained with hematoxylin.

Using a combined scoring system which was based on the sum of nucleus staining intensity and the percentage of positive cells, the final evaluation of ambiguous cases was decided after discussion the investigators. Scores from 0 to 3 were given for the staining intensity and the percentage of positive cells as follows: score of 0 , no staining detected, or was observed in less than $10 \%$ of the tumor cells; score of $1+$, weak staining observed in $10 \%$ or more of the tumor cells; score of $2+$, moderate staining was observed in $10 \%$ or more of the tumor cells; and score of $3+$, strong staining was observed in $10 \%$ or more of the tumor cells. Scores of 0 and
$1+$ were considered to be negative, whereas scores of $2+$ and $3+$ were considered to be positive for overexpression (17).

\section{Statistical analysis}

All statistical analyses were performed by using the SPSS 22.0 statistical software package and the association between protein expression and clinicopathological variables was analyzed using the $\chi^{2}$ test or Fisher's exact test. ROC curve was used to evaluate the feasibility of PRL, PIGF, and NGFR as diagnostic tools for detecting malignant and healthy controls. Survival curves were plotted by using the Kaplan-Meier method and compared using a log-rank test. The $\mathrm{P}<0.05$ were considered to be significant.

\section{Results}

\section{Expression of PRL, PIGF and NGFR protein chip detection in plasma}

The serum samples were available for 3 patients. Markers detection included 440 cytokines, growth factors, proteases, soluble receptors and other proteins. The results were grouped together based on known associations with tumor growth, angiogenesis and immune activation (Table 1). By measuring protein levels, PRL, PIGF, and NGFR at ESCC/ Normal ratios of 4.46, 6.23, and 2.16. PRL, PIGF and NGFR weren't reported in ESCC by consulting relevant literature.

\section{The levels PRL, PIGF and NGFR in the plasma of ESCC patients}

The further experimental results confirmed that the expression of PRL, PIGF and NGFR in plasma of ESCC was higher than that of the control group by ELISA. Moreover, the expression of three proteins in plasma was down-regulated after effective tumor-related treatment, such as chemotherapy, radiotherapy and surgery (Figure 1).

\section{Association of PRL, PIGF and NGFR expression in plasma clinicopathological parameters}

Correlations between the expression of protein and clinicopathological factors were illustrated (Table 2). In ESCC patients, the results showed that PRL and NGFR was statistically significant in different tumor classifications $\left(\chi^{2}=4.694, \mathrm{P}=0.030\right)$ and $\left(\chi^{2}=4.332, \mathrm{P}=0.037\right)$, while both 
Table 1 Plasma protein chip screening results of ESCC

\begin{tabular}{|c|c|c|c|}
\hline Name & $\begin{array}{l}\text { Normal } \\
\text { (pg/mL) }\end{array}$ & $\begin{array}{l}\text { ESCC } \\
(\mathrm{pg} / \mathrm{mL})\end{array}$ & $\begin{array}{c}\text { Ratio (ESCC/ } \\
\text { normal) }\end{array}$ \\
\hline Epo R & 57.10 & 0.00 & 0 \\
\hline Thrombospondin-5 & 969.26 & 0.00 & 0 \\
\hline TLR4 & $181,633.37$ & $1,015.72$ & 0.01 \\
\hline TLR2 & $11,899.83$ & 613.43 & 0.05 \\
\hline FGF-21 & $2,386.12$ & 124.38 & 0.05 \\
\hline OPN & $17,506.71$ & $1,304.83$ & 0.07 \\
\hline MIP-3b & 461.14 & 56.31 & 0.12 \\
\hline BAFF & $27,240.76$ & $11,802.68$ & 0.43 \\
\hline FAS L & 76.52 & 37.28 & 0.49 \\
\hline IFNab R2 & $11,224.48$ & $24,193.51$ & 2.16 \\
\hline NGFR & 532.44 & $1,149.47$ & 2.16 \\
\hline TSP-1 & $15,542.96$ & $36,782.15$ & 2.37 \\
\hline TGFb3 & 22.39 & 54.30 & 2.42 \\
\hline CD14 & 727.62 & $1,808.55$ & 2.49 \\
\hline Insulin & $1,616.22$ & $4,447.90$ & 2.75 \\
\hline b-NGF & 2.90 & 8.26 & 2.85 \\
\hline IL-2 Rg & $2,682.03$ & $7,955.29$ & 2.97 \\
\hline IL-7 & 35.66 & 122.49 & 3.43 \\
\hline TNFa & 350.00 & $1,202.67$ & 3.44 \\
\hline NT-4 & 70.48 & 249.82 & 3.54 \\
\hline VEGF-C & 61.02 & 217.72 & 3.57 \\
\hline IL-6 & 21.36 & 76.54 & 3.58 \\
\hline NT-3 & 75.28 & 278.04 & 3.69 \\
\hline VEGF R3 & 242.77 & 910.01 & 3.75 \\
\hline HGF & 330.25 & $1,258.20$ & 3.81 \\
\hline FGF-19 & 191.67 & 794.24 & 4.14 \\
\hline PRL & $73,111.87$ & $326,015.88$ & 4.46 \\
\hline IL-2 & 71.01 & 320.05 & 4.51 \\
\hline IL-8 & 52.75 & 242.11 & 4.59 \\
\hline PDGF-AA & 163.54 & 784.26 & 4.8 \\
\hline LIGHT & 105.46 & 591.12 & 5.61 \\
\hline FGF-7 & 28.27 & 159.09 & 5.63 \\
\hline MIP-1b & 3.99 & 24.20 & 6.06 \\
\hline PIGF & 28.17 & 175.45 & 6.23 \\
\hline
\end{tabular}

Table 1 (continued)
Table 1 (continued)

\begin{tabular}{lccc}
\hline Name & $\begin{array}{c}\text { Normal } \\
(\mathrm{pg} / \mathrm{mL})\end{array}$ & $\begin{array}{c}\text { ESCC } \\
(\mathrm{pg} / \mathrm{mL})\end{array}$ & $\begin{array}{c}\text { Ratio (ESCC/ } \\
\text { normal) }\end{array}$ \\
\hline IL-4 & 5.26 & 37.52 & 7.14 \\
G-CSF & 56.01 & 487.21 & 8.7 \\
LAP(TGFb1) & 374.96 & $3,399.20$ & 9.07 \\
VEGF & 63.48 & 636.24 & 10.02 \\
BDNF & 30.97 & 330.40 & 10.67 \\
RANK & $5,421.02$ & $93,477.48$ & 17.24 \\
ANG-1 & 646.57 & $12,097.90$ & 18.71 \\
IL-1 RI & 238.29 & $4,680.77$ & 19.64 \\
IL-1a & 2.69 & 66.70 & 24.84 \\
G-CSF R & 63.46 & $2,854.16$ & 44.97 \\
EGF & 2.14 & 127.92 & 59.68 \\
MCP-4 & 0.23 & 14.56 & 64.32 \\
SDF-1a & 0.01 & 23.31 & 1662.05 \\
P value & & & $<0.05$ \\
\hline
\end{tabular}

PRL, prolactin; PIGF, placenta growth factor; NGFR, nerve growth factor receptor; ESCC, esophageal squamous cell carcinoma.

of them were not associated with clinical pathological parameters such as gender, age, clinical stage, and lymph node metastasis. The expression of PIGF was statistically significant in different clinical stages $\left(\chi^{2}=11.377, \mathrm{P}=0.001\right)$. There was no significant difference in expression between age, gender, tissue grade, and lymph node metastasis.

\section{Sensitivity and specificity detection of PRL, PIGF and NGFR in plasma of patients}

The sensitivity and specificity of the 3 markers were determined using ROC curves, and the AUC was calculated (Figure 2). The combined detection included group one $(\mathrm{PRL}+\mathrm{PIGF})$, group two (PRL + NGFR), group three $(\mathrm{PIGF}+\mathrm{NGFR})$, group four (PRL + PIGF + NGFR). The sensitivity $(64.5 \%)$ of PRL was the highest of the single detection, from which ACU was 0.69. But the specificity (71.7\%) of PRL was lower than NGFR which specificity was $44.5 \%$ and sensitivity was $73.4 \%$ in separately. The ACU of NGFR was 0.66 . The sensitivity and specificity of PIGF were $51.8 \%$ and $59.8 \%$, respectively. The ACU was 0.72 . There was not only the highest specificity $(66.7 \%)$, but 

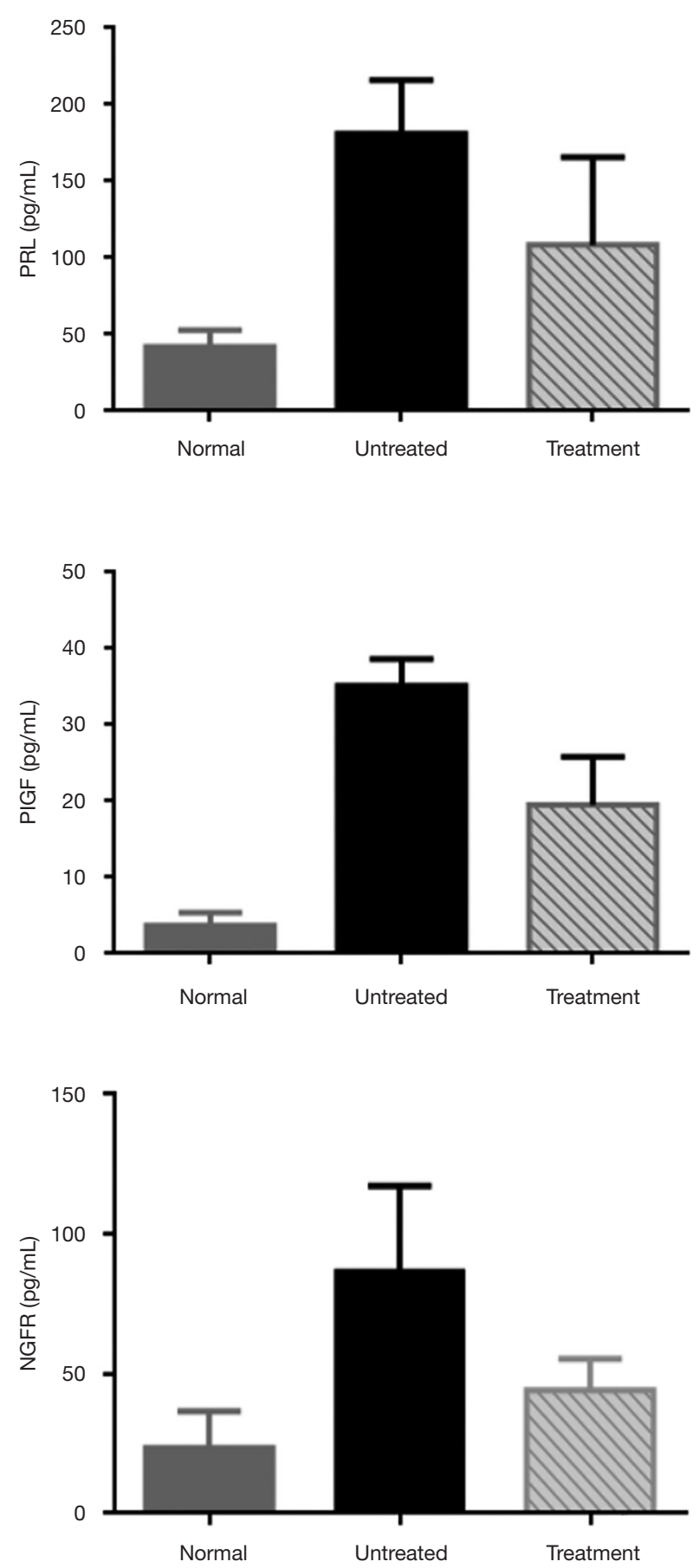

Figure 1 Comparison of expression in plasma between normal and ESCC in untreated group and treated group (A: PRL; B: PIGF; C: NGFR). PRL, prolactin; PIGF, placenta growth factor; NGFR, nerve growth factor receptor; ESCC, esophageal squamous cell carcinoma. also a good sensitivity $(72.4 \%)$ in the 3 different combined detection groups, and the AUC (0.74) was the largest at the same time in the fourth group (PRL + PIGF + NGFR).

\section{Expression of PRL and PIGF in ESCC and adjacent tissue}

To further corroborate the above findings, we compared the positive level of PRL, PIGF and NGFR in tissue sections (Figure 3). IHC was used to detect the expression of protein in ESCC and adjacent tissue (Table 3). The above studies confirmed that the positive expression rates of PRL, PIGF and NGFR in ESCC were higher than those in adjacent tissue.

\section{Correlations between PRL, PIGF and NGFR expression and clinicopathological factors in tissue}

In the ESCC patients, PRL $(\mathrm{P}=0.048)$ and NGFR $(\mathrm{P}=0.028)$ were related to tumor classification. No association with gender, age, clinical stage, or lymph node metastasis was found (Table 4). The expression of PIGF ( $\mathrm{P}=0.022$ ) was associated with clinical stages rather than gender, age, tissue grading, or lymph node metastasis.

\section{Relationship among expressions of PRL, PIGF and NGFR and survival time}

The disease of free survival time of PRL-positive patients is shorter than that of PRL-negative patients. The difference between the two groups is statistically significant by KaplanMeier $(\mathrm{P}<0.01)$. Similar results are shown in PIGF and NGFR (Figure 4).

\section{Discussion}

PRL is a secreted protein both in human blood and tissues (18). We found that PRL was highly expressed in ESCC than in normal human and positively associated with tumor classification in plasma and adjacent tissue, and we confirmed that the sensitivity and specificity of PRL was $64.5 \%$ and $71.7 \%$ (19). Researcher has confirmed that activated PRL receptors (PRLR) can lead to tumor cell proliferation and differentiation (20). Some scholars also confirmed that PRL was associated with tumor classification $(12,21,22)$, which was consistent with the results of our 
Table 2 Expression of PRL, PIGF and NGFR in ESCC and analysis of clinicopathological parameters

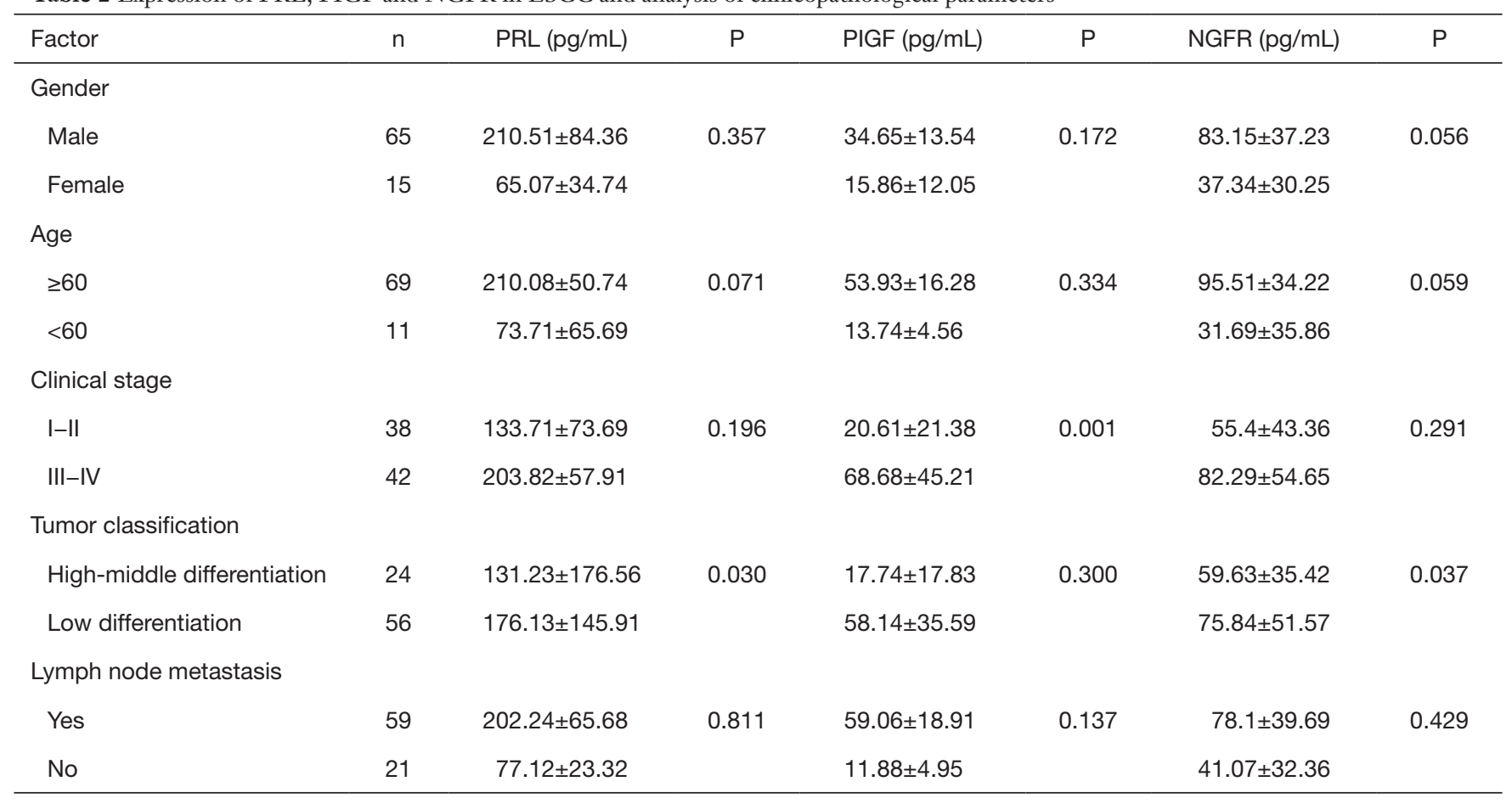

PRL, prolactin; PIGF, placenta growth factor; NGFR, nerve growth factor receptor; ESCC, esophageal squamous cell carcinoma.

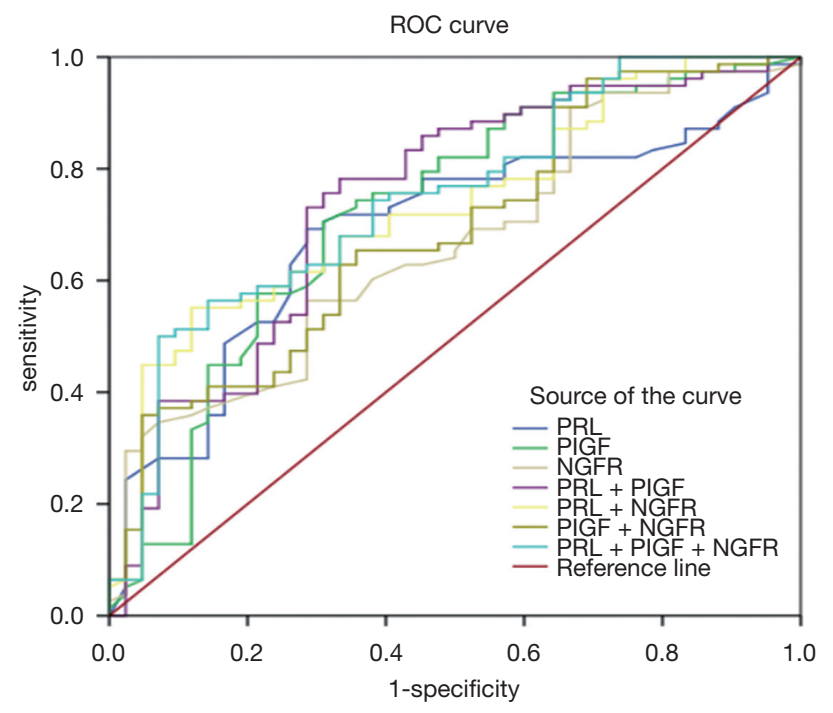

Figure 2 ROC curves for the combinations of the PRL, PIGF and NGFR protein. PRL, prolactin; PIGF, placenta growth factor; NGFR, nerve growth factor receptor.

experiment. Moreover, PRL antagonists (selective PRLR modulator S179DPRL) inhibited cell growth and promoted differentiation in vitro and vivo (23). Studies reported that PRL played as a cytokine in human T cell-mediated immune responses, which was currently a hot topic for studying tumor-targeted therapy (24). PRL might be an important factor influencing the number of cells, and PRL has a great dependence on tumor growth $(18,25)$. Overexpression of PRL in ESCC tissues associates with a poorer survival rate, which may consider as a biomarker of survival prediction and a potential new therapeutic target.

Many previous studies concerning PIGF played an important role in tumor initiation, progression, metastasis, cancer recurrence and therapeutic resistance as a secreted glycoprotein $(25,26)$. PIGF promoted blood vessel by binding and neutralizing the angiogenesis inhibitory receptor (Soluble fms-like tyrosine kinase receptor-1, sFlt1) which is the key role in generation (26). In the present study, we showed that PIGF might be related to clinical stage in plasma and tissue. Some studies showed that in addition to the formation of homodimers, heterodimers formed by PIGF and VEGF, contrary to previous evidences, tumor angiogenesis was inactive (27-29). In addition, previous studies have confirmed that the knockdown of PIGF gene in gastric cancer can reduce angiogenesis, cell migration and invasion (30,31). There was evidence that PIGF stimulated tumor growth by increasing blood 


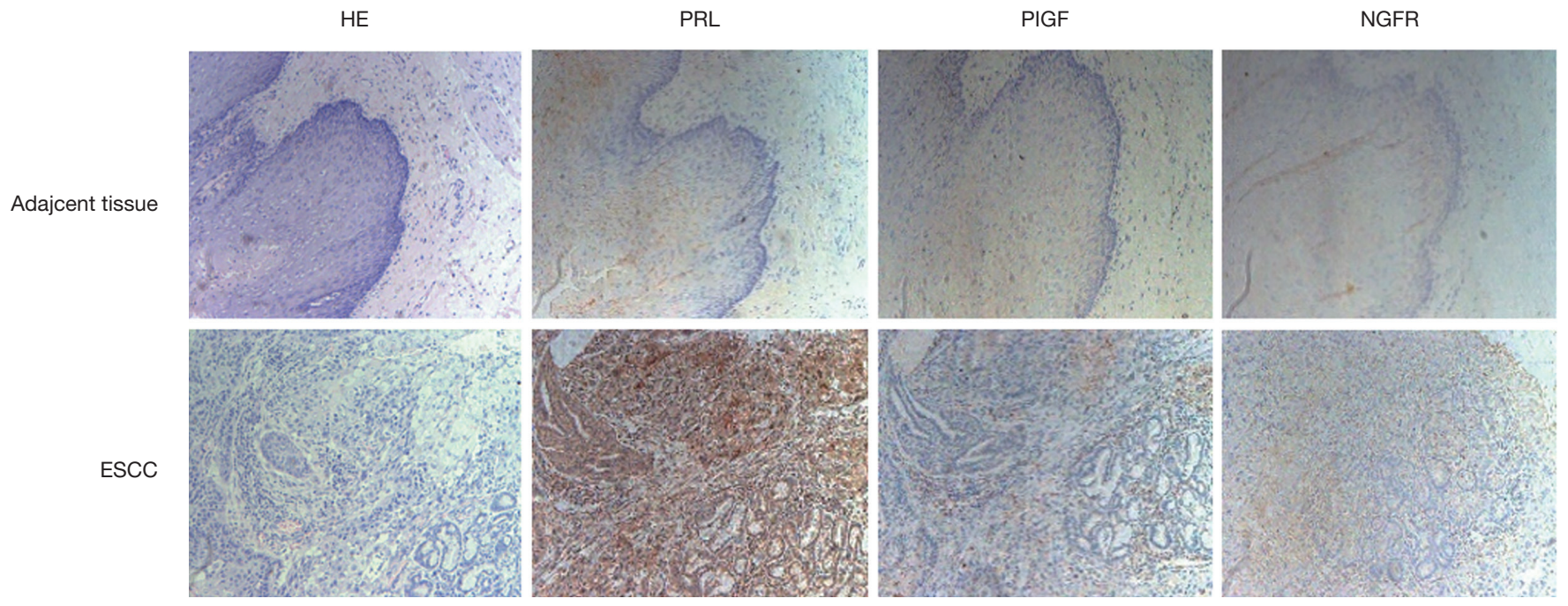

Figure 3 Representative results of IHC of PRL, PIGF and NGFR in adjacent tissue and ESCC (original magnification, 10×40). PRL, prolactin; PIGF, placenta growth factor; NGFR, nerve growth factor receptor; IHC, immunohistochemistry; ESCC, esophageal squamous cell carcinoma.

Table 3 Comparison of PRL and PIGF, NGFR expression in ESCC and adjacent tissue

\begin{tabular}{|c|c|c|c|c|c|c|c|c|c|c|c|c|c|}
\hline \multirow{2}{*}{ Group } & \multirow{2}{*}{$n$} & \multicolumn{4}{|c|}{ PRL } & \multicolumn{4}{|c|}{ PIGF } & \multicolumn{4}{|c|}{ NGFR } \\
\hline & & + & - & $\chi^{2}$ & $\mathrm{P}$ & + & - & $\chi^{2}$ & $\mathrm{P}$ & + & - & $\chi^{2}$ & $\mathrm{P}$ \\
\hline Adjacent & 15 & 0 & 15 & 25.109 & 0.000 & 3 & 12 & 8.636 & 0.003 & 2 & 13 & 7.767 & 0.005 \\
\hline ESCC & 68 & 48 & 20 & & & 42 & 26 & & & 36 & 32 & & \\
\hline
\end{tabular}

PRL, prolactin; PIGF, placenta growth factor; NGFR, nerve growth factor receptor; ESCC, esophageal squamous cell carcinoma.

vessel growth and maturation, whereas inhibition of PIGF reduced angiogenesis in various cancers (25). This might suggest that PIGF promoted tumor blood vessel growth by promoting tumor invasion and affecting clinical stage of patients and OS.

We revealed that the expression of NGFR in ESCC was higher than healthy controls in plasma and adjacent tissue. Some researchers confirmed that NGFR induces tumor tissue differentiation and was associated with tumor classification, furthermore malignancy of the tumor (32). NGFR inhibition could increase the anti-apoptotic ability of tumor cells (33). Some previous studies had examined the NGFR was overexpression in highly aggressive and metastatic malignancies, and had greater tumor initiating ability in vivo than normal cell (34-36). However, in this study, there were no effects of NGFR on the prognosis of patients with esophageal cancer (EC), which may due to the retrospective nature of the study and the small sample size. Some scholars showed that the inhibition of NGFR might contributes to the increase of protein level, and thus the cell resistance to apoptosis is also enhanced $(37,38)$.

There were several potential limitations that warrant consideration in our study. The present data had uncertainness because AUC of PRL, PIGF and NGFR were moderate accuracy $(0.69,0.72$ and 0.66 , respectively) in cut-off value determined by ROC analysis. The study was limited by the small number of adjacent tissue that were examined, and its retrospective nature.

Based on the above studies, PIGF protein was related to the clinical stage of ESCC patients by hematological and histological examination. The PRL and NGFR proteins were related to the tissue classification of ESCC patients, and the specific mechanism needed to be further confirmed. PRL, PIGF and NGFR play an important role in the occurrence and progression of ESCC. They had important reference significance for enriching EC tumor markers and explored new targets for EC, which would improve the efficacy and survival rate of esophageal cancer. 
Table 4 Correlation between expression of determined PRL, PIGF and NGFR by IHC and clinicopathological features in patients

\begin{tabular}{|c|c|c|c|c|c|c|c|c|c|c|}
\hline Factor & $n$ & \multicolumn{3}{|c|}{ PRL } & \multicolumn{3}{|c|}{ PIGF } & \multicolumn{3}{|c|}{ NGFR } \\
\hline \multicolumn{11}{|l|}{ Gender } \\
\hline Male & 53 & 36 & 17 & 0.365 & 34 & 19 & 0.501 & 26 & 27 & 0.227 \\
\hline Female & 15 & 12 & 3 & & 9 & 7 & & 10 & 5 & \\
\hline$\geq 60$ & 35 & 23 & 12 & 0.364 & 19 & 16 & 0.191 & 16 & 19 & 0.219 \\
\hline$<60$ & 33 & 25 & 8 & & 23 & 10 & & 20 & 13 & \\
\hline \multicolumn{11}{|l|}{ Clinical stage } \\
\hline I-II & 38 & 29 & 11 & 0.819 & 28 & 10 & 0.022 & 17 & 21 & 0.127 \\
\hline High-middle differentiation & 33 & 27 & 6 & 0.048 & 21 & 12 & 0.758 & 22 & 11 & 0.028 \\
\hline Low differentiation & 35 & 21 & 14 & & 21 & 14 & & 14 & 21 & \\
\hline \multicolumn{11}{|l|}{ Lymph node metastasis } \\
\hline Yes & 28 & 19 & 9 & 0.679 & 14 & 14 & 0.069 & 17 & 11 & 0.283 \\
\hline No & 40 & 29 & 11 & & 28 & 12 & & 19 & 21 & \\
\hline
\end{tabular}

PRL, prolactin; PIGF, placenta growth factor; NGFR, nerve growth factor receptor.
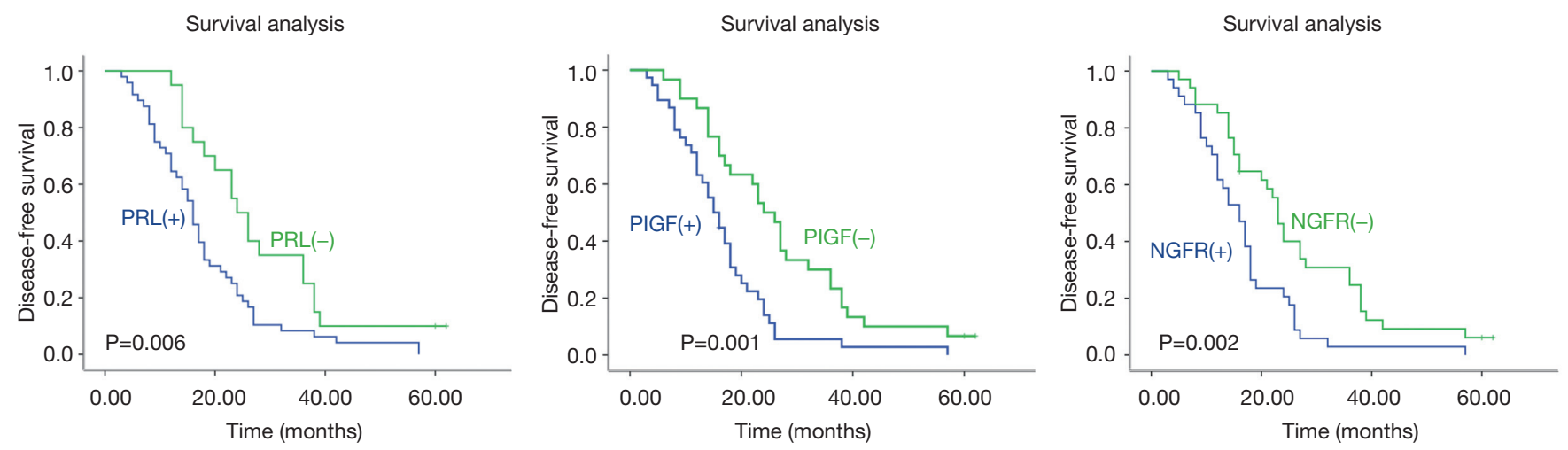

Figure 4 Relationship among expressions of PRL, PIGF and NGFR and disease of free survival time. PRL, prolactin; PIGF, placenta growth factor; NGFR, nerve growth factor receptor.

\section{Conclusions}

We have demonstrated that the expressions of PRL, PIGF and NGFR in plasma and tissue are higher than that of the control group. This will help early diagnosis of ESCC and is related to the patient's prognosis. Therefore, PRL, PIGF and NGFR can be used as biomarkers for early diagnosis and prognosis in patients with ESCC.

\section{Acknowledgments}

Funding: This work was supported by National Nature Science Foundation of China (81272960), Key Research Program from Science and Technology Department of Hunan Province, China (2017SK2082), the Key Research Program from the Science and Technology Department of Ningxia Hui Autonomous Region, China (2019BFH02012); 
the Key Research Program of Hunan Health Committee, China (20201909).

\section{Footnote}

Conflicts of Interest: All authors have completed the ICMJE uniform disclosure form (available at http://dx.doi. org/10.21037/tcr.2019.12.31). The authors have no conflicts of interest to declare.

Ethical Statement: The authors are accountable for all aspects of the work in ensuring that questions related to the accuracy or integrity of any part of the work are appropriately investigated and resolved. The study was conducted in accordance with the Declaration of Helsinki (as revised in 2013). The study was approved by ethics committee of the First Affiliated Hospital of University of South China (No. 2016037). Informed consent was obtained from all individual participants included in the study.

Open Access Statement: This is an Open Access article distributed in accordance with the Creative Commons Attribution-NonCommercial-NoDerivs 4.0 International License (CC BY-NC-ND 4.0), which permits the noncommercial replication and distribution of the article with the strict proviso that no changes or edits are made and the original work is properly cited (including links to both the formal publication through the relevant DOI and the license). See: https://creativecommons.org/licenses/by-nc$\mathrm{nd} / 4.0 \%$.

\section{References}

1. Lagergren J, Smyth E, Cunningham D, et al. Oesophageal cancer. Lancet 2017;390:2383-96.

2. Codipilly DC, Qin Y, Dawsey SM, et al. Screening for esophageal squamous cell carcinoma: recent advances. Gastrointest Endosc 2018;88:413-26.

3. Peerlings J, Van De Voorde L, Mitea C, et al. Hypoxia and hypoxia response-associated molecular markers in esophageal cancer: A systematic review. Methods 2017;130:51-62

4. Yeo SY, Ha SY, Lee KW, et al. Twist1 is highly expressed in cancer-associated fibroblasts of esophageal squamous cell carcinoma with a prognostic significance. Oncotarget 2017;8:65265-80

5. Shah MA. Future Directions in Improving Outcomes for
Patients with Gastric and Esophageal Cancer. Hematol Oncol Clin North Am 2017;31:545-52.

6. Yoo BC, Kim KH, Sang MW, et al. Clinical multiomics strategies for the effective cancer management. J Proteomics 2018;188:97-106.

7. Yang YS, Hu WP, Wang WP, et al. Nodal Skip Metastasis: A Promising Predictor of Prognosis in ESCC. Ann Thorac Surg 2018;106:1593-4.

8. Liu L, Yang Z, Ni W, et al. ADAMTS-6 is a predictor of poor prognosis in patients with esophageal squamous cell carcinoma. Exp Mol Pathol 2018;104:134-9.

9. Sato Y, Motoyama S, Wakita A, et al. TLR3 expression status predicts prognosis in patients with advanced thoracic esophageal squamous cell carcinoma after esophagectomy. Am J Surg 2018;216:319-25.

10. di Pietro M, Canto MI, Fitzgerald RC. Endoscopic Management of Early Adenocarcinoma and Squamous Cell Carcinoma of the Esophagus: Screening, Diagnosis, and Therapy. Gastroenterology 2018;154:421-36.

11. Kristo I, Riegler M, Schoppmann SF. Endoscopic Therapy for Barrett's Esophagus: Who and How. Surgery for Benign Oesophageal Disord 2018;20:55-61.

12. Castillo LF, Rivero EM, Goffin V, et al. Alpha 2-adrenoceptor agonists trigger prolactin signaling in breast cancer cells. Cell Signal 2017;34:76-85.

13. Coleman HG, Xie SH, Lagergren J. The Epidemiology of Esophageal Adenocarcinoma. Gastroenterology 2018;154:390-405.

14. Fitzgerald RC, Vaezi MF. Esophageal Diseases. Gastroenterology 2018;154:263-6.

15. Hayes T, Smyth E, Riddell A, et al. Staging in Esophageal and Gastric Cancers. Hematol Oncol Clin North Am 2017;31:427-40.

16. Wittekind C, Oberschmid B. TNM-Klassifikation maligner Tumoren 2010. Pathologe 2010;31:333-8.

17. Zuo J, Wen M, Lei M, et al. MiR-210 Links Hypoxia With Cell Proliferation Regulation in Human Laryngocarcinoma Cancer. J Cell Biochem 2015;116:1039.

18. Chen KE, Walker AM. Prolactin inhibits a major tumorsuppressive function of wild type BRCA1. Cancer Lett 2016;375:293-302.

19. Karthikeyan S, Russo A, Dean M, et al. Prolactin signaling drives tumorigenesis in human high grade serous ovarian cancer cells and in a spontaneous fallopian tube derived model. Cancer Lett 2018;433:221-31.

20. Gangadharan A, Nyirenda T, Patel K, et al. Prolactin Induced Protein (PIP) is a potential biomarker for early stage and malignant breast cancer. Breast 2018;39:101-9. 
21. Kavarthapu R, Dufau ML. Essential role of endogenous prolactin and cdk7 in estrogen-induced upregulation of the prolactin receptor in breast cancer cells. Oncotarget 2017;8:27353-63.

22. Lee PY, Chin SF, Low TY, et al. Probing the colorectal cancer proteome for biomarkers: Current status and perspectives. J Proteomics 2018;187:93-105.

23. Kavarthapu R, Dufau ML. Essential role of endogenous prolactin and CDK7 in estrogen-induced upregulation of the prolactin receptor in breast cancer cells. Oncotarget 2017;8:27353-63.

24. Foy M, Anézo O, Saule S, et al. PRL-3/PTP4A3 phosphatase regulates integrin $\beta 1$ in adhesion structures during migration of human ocular melanoma cells. Exp Cell Res 2017;353:88-99.

25. Abbas M, Faggian A, Sintali DN, et al. Current and future biomarkers in gastric cancer. Biomed. Pharmacother 2018;103:1688-700.

26. Newell LF, Holtan SG. Placental growth factor: What hematologists need to know. Blood Rev 2017;31:57-62.

27. Macklin PS, Mcauliffe J, Pugh CW, et al. Hypoxia and HIF pathway in cancer and the placenta. Placenta 2017;56:8-13.

28. Alonso V, Escudero P, Fernández-Martos C, et al. Coexpression of p-IGF-1R and MMP-7 Modulates Panitumumab and Cetuximab Efficacy in RAS WildType Metastatic Colorectal Cancer Patients. Neoplasia 2018;20:678-86.

29. Marech I, Leporini C, Ammendola M, et al. Classical and non-classical proangiogenic factors as a target of antiangiogenic therapy in tumor microenvironment. Cancer Lett 2016;380:216-26.

30. Roskoski R. Vascular endothelial growth factor (VEGF)

Cite this article as: $\mathrm{Ai} \mathrm{X}, \mathrm{Zhu} \mathrm{X}, \mathrm{Zuo} \mathrm{J}$. Prolactin (PRL), placenta growth factor (PIGF) and nerve growth factor receptor (NGFR) as biomarkers for early diagnosis and prognosis in patients with esophageal squamous cell carcinoma (ESCC). Transl Cancer Res 2020;9(2):647-656. doi: 10.21037/ tcr.2019.12.31 and VEGF receptor inhibitors in the treatment of renal cell carcinomas. Pharmacol Res 2017;120:116-32.

31. Pauty J, Usuba R, Cheng IG, et al. A Vascular Endothelial Growth Factor-Dependent Sprouting Angiogenesis Assay Based on an In Vitro Human Blood Vessel Model for the Study of Anti-Angiogenic Drugs. Ebiomedicine 2018;27:225-36.

32. Huang P, Tong D, Sun J, et al. Generation and characterization of a human oral squamous carcinoma cell line SCC-9 with CRISPR/Cas9-mediated deletion of the p75 neurotrophin receptor. Arch Oral Biol 2017;82:223-32.

33. Aghdaei FH, Soltani BM, Dokanehiifard S, et al. Overexpression of hsa-miR-939 follows by NGFR downregulation and apoptosis reduction. J Biosci 2017;42:23.

34. Wu V, Auchman M, Mollica PA, et al. ALDH1A1 positive cells are a unique component of the tonsillar crypt niche and are lost along with NGFR positive stem cells during tumourigenesis. Pathology 2018;50:524-9.

35. Chakravarthy R,Mnich K,Gorman A M. Nerve growth factor (NGF)-mediated regulation of p75(NTR) expression contributes to chemotherapeutic resistance in triple negative breast cancer cells. Biochem Biophys Res Commun 2016;478:1541-7.

36. Chen C, Shin JH, Eggold JT, et al. ESM1 mediates NGFR-induced invasion and metastasis in murine oral squamous cell carcinoma. Oncotarget 2016;7:70738-49.

37. Griffin N, Faulkner S, Jobling P, et al. Targeting neurotrophin signaling in cancer: the renaissance. Pharmacol Res 2018;135:12-7.

38. Jeong S, Zheng B, Wang H, et al. Nervous system and primary liver cancer. Biochim Biophys Acta Rev Cancer 2018;1869:286-92. 